University of Wollongong

Research Online

Australian Institute for Innovative Materials -

Papers

Australian Institute for Innovative Materials

$1-1-2018$

Formation of hollow MoS2/carbon microspheres for high capacity and high rate reversible alkali-ion storage

Tianyu Yang

Deakin University, University of Queensland

Ji Liang

University of Wollongong, liangj@uow.edu.au

Irin Sultana

Deakin University, is988@uow.edu.au

Md. Mokhlesur Rahman

Deakin University, mrahman@uow.edu.au

Michael J. Monteiro

University of Queensland

See next page for additional authors

Follow this and additional works at: https://ro.uow.edu.au/aiimpapers

Part of the Engineering Commons, and the Physical Sciences and Mathematics Commons

Research Online is the open access institutional repository for the University of Wollongong. For further information contact the UOW Library: research-pubs@uow.edu.au 


\title{
Formation of hollow MoS2/carbon microspheres for high capacity and high rate reversible alkali-ion storage
}

\author{
Abstract \\ Nanocomposites of carbon and molybdenum disulfide have attracted much attention due to their \\ significant potential in energy conversion and storage applications. However, the preparation of these 0-D \\ MoS 2 /carbon composites with controllable structures and desirable properties remains a major \\ manufacturing challenge, particularly at low cost suitable for scaling-up. Here, we report a facile solution- \\ based method to prepare porous hierarchical 0-D MoS 2 /carbon nanocomposites with vertical MoS 2 \\ growth on a hollow carbon support, suitable for the electrochemical storage of lithium and sodium ions. \\ The vertically aligned MoS 2 /hollow carbon material shows excellent performance in the storage of a \\ series of alkali-metal ions (e.g. $\mathrm{Li}+, \mathrm{Na}+$, and $\mathrm{K}+$ ) with high capacity, excellent rate capacity, and stable \\ cyclability. When used for the storage of $\mathrm{Li}+$ ions, it possesses a high capacity of over $800 \mathrm{~mA} \mathrm{~h} \mathrm{g-1}$ at a \\ rate of $100 \mathrm{~mA} \mathrm{~g}-1$, with a negligibly small capacity decay as low as $0.019 \%$ per cycle. At a substantially \\ higher rate of $5 \mathrm{~A} \mathrm{~g} \mathrm{-1}$, this MoS 2 /carbon nanocomposite still delivers a capacity of over $540 \mathrm{~mA} \mathrm{~h} \mathrm{~g}-1$, \\ showing its excellent performance at high rates. Remarkably, this material uniquely delivers high \\ capacities of over $450 \mathrm{~mA} \mathrm{~h} \mathrm{g-1}$ and $300 \mathrm{~mA} \mathrm{~h} \mathrm{~g}-1$ for $\mathrm{Na}+$ and $\mathrm{K}+$ ion storage, respectively, which are \\ among the highest values reported to date in the literature. These excellent characteristics confirm the \\ hollow MoS 2 /carbon nanocomposites to be a primary contender for next generation secondary \\ batteries. \\ Disciplines \\ Engineering | Physical Sciences and Mathematics

\section{Publication Details} \\ Yang, T., Liang, J., Sultana, I., Rahman, M., Monteiro, M. J., Chen, Y., Shao, Z., Silva, S. Ravi. P. \& Liu, J. \\ (2018). Formation of hollow MoS2/carbon microspheres for high capacity and high rate reversible alkali- \\ ion storage. Journal of Materials Chemistry A, 6 (18), 8280-8288.
}

\section{Authors}

Tianyu Yang, Ji Liang, Irin Sultana, Md. Mokhlesur Rahman, Michael J. Monteiro, Ying I. Chen, Zongping Shao, S Ravi. P Silva, and Jian Liu 


\section{Journal Name}

\section{ARTICLE}

\section{Formation of Hollow $\mathrm{MoS}_{2}$ /Carbon Microspheres for High Capacity and High Rate Reversible Alkali-Ion Storage}

Received 00th January 20xx, Accepted 00th January 20xx DOI: $10.1039 / \times 0 \times x 00000 x$

www.rsc.org/

\author{
Tianyu Yang, ${ }^{\text {a, }} \neq \neq$ Ji Liang, ${ }^{c \ddagger}$ Irin Sultana, ${ }^{a}$ Md Mokhlesur Rahman, ${ }^{a}$ Michael J. Monteiro, ${ }^{b}$ Ying (Ian)
} Chen, ${ }^{* a}$ Zongping Shao, ${ }^{* d, e}$ S. Ravi P. Silva ${ }^{f}$ and Jian Liu*b,e,f,g

\section{Introduction}

In recent years, there has been a significant increase in demand for the development of materials and devices with high energy storage density and power density, for use in portable electronics, electric vehicles, or stationary power grids, etc. Among the various energy storage devices, lithium ion batteries (LIBs) are the most successfully commercialized and widely used batteries worldwide. In a typical LIB,

a. Institute for Frontier Materials, Deakin University, Geelong, VIC 3216, Australia

b. Australian Institute for Bioengineering and Nanotechnology, The University of Queensland, Brisbane, QLD 4072, Australia

Institute for Superconducting \& Electronic Materials, Australian Institute of Innovative Materials, University of Wollongong, Innovation Campus, Squires Way, North Wollongong, NSW 2500, Australia

d. Jiangsu National Synergetic Innovation Center for Advanced Materials, College of Chemical Engineering, Nanjing Tech University, No.5 Xin Mofan Road, Nanjing, 210009, PR China

e. Department of Chemical Engineering, Curtin University, Perth, WA 6845, Australia f. Advanced Technology Institute \& Department of Chemical and Process Engineering, University of Surrey, Guildford, Surrey, GU2 7XH, UK

g. State Key Laboratory of Catalysis, Dalian Institute of Chemical Physics, Chinese Academy of Sciences, 457 Zhongshan Road, Dalian 116023, China

* Corresponding authors: ian.chen@deakin.edu.au; zongping.shao@curtin.edu.au; jian.liu@surrey.ac.uk

+ Electronic Supplementary Information (ESI) available: TEM image of RF@MoS The Raman spectra, XRD spectra, TGA spectra, nitrogen adsorption-desorption isotherms and the first charge-discharge profiles of the samples. The cycling stability of $\mathrm{MOS}_{2} / \mathrm{C}-0.3$ sample tested for 200 cycles. The LIB CV profile of $\mathrm{MoS}_{2} / \mathrm{C}$ 0.3 sample. The SIB and PIB evaluation profiles including CV, cycling stability and charge-discharge profiles of the sample ${\mathrm{C} @ M o S_{2}-0.3 \text {. See }}$ DOI: $10.1039 / x 0 x \times 00000 x$ electricity is stored and released by the reversible insertion and desertion of $\mathrm{Li}^{+}$at the anode (e.g. graphite) and cathode (e.g. $\mathrm{LiFePO}_{4}$ and $\mathrm{LiMO}_{2}$ where $\mathrm{M}$ represents either metallic Co, $\mathrm{Mn}, \mathrm{Ni}$, or their mixtures) materials. ${ }^{1-6}$ In order to further improve the energy density of LIBs, novel battery materials continue to progress with higher capacity in both the anode and cathode electrodes. Molybdenum disulfide $\left(\mathrm{MoS}_{2}\right)$, a twodimensional transition-metal sulfide layered material, is considered among the most promising anode materials for the next generation LIBs due to its high lithium storage capacity of up to $670 \mathrm{mAh} \mathrm{g}^{-1}$, versatility in microstructure, and ease of synthesis. ${ }^{7-9}$

Furthermore, battery systems using alkali metal (i.e. Na and K) species with higher earth abundancy than Li, have been recently studied with the purpose of finding alternative energy storage solutions to LIBs. However, the larger dimensions of these alternative ions, will not provide satisfactory capacity with the conventional anode materials used in LIBs. As a result, alternative electrode materials with larger interlayer spacing have been proposed for the storage of these alkali metal ions. ${ }^{10-13}$ 

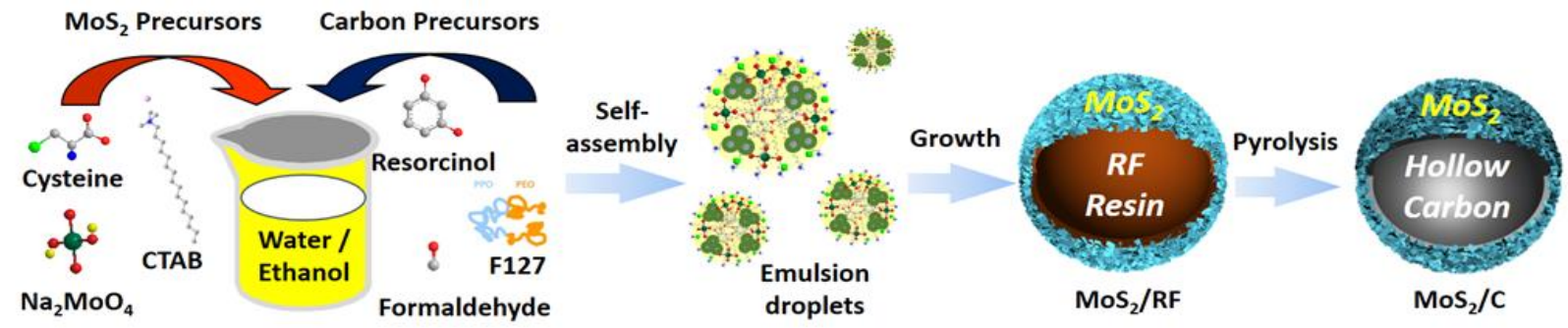

Fig. 1 Schematic diagram of the one-pot synthetic protocol of $\mathrm{MoS}_{2} /$ carbon composite hollow nanosphere.

Among them, the $\mathrm{MoS}_{2}$-based materials are especially attractive, not only due to their much larger interlayer distance, but also their facileness to be synthesized into welldefined nanostructures that further augment performance. For example, to deal with the poor electronic conductivity and large volume variations during the insertion and extraction of the metal ions, ${ }^{8,14} \mathrm{MoS}_{2}$ has been constructed into a diverse range of nanostructures that buffer the stress during charge and discharge. ${ }^{16}$ In the meantime, carbons or other conductive substrates have been incorporated to form composites with different geometries and dimensions, including 0-dimension (0-D) $\mathrm{MoS}_{2}$ /carbon nanoparticles or hollow $\mathrm{MoS}_{2} /$ carbon nanospheres, 17-20 1-dimensional (1-D) $\mathrm{MoS}_{2}$ /carbon nanofibers or nanotubes composites, ${ }^{21}, 22$ 2dimensional (2-D) $\mathrm{MoS}_{2}$ /graphene composites, ${ }^{23-26}$ or their macroscopic assemblies (3-D). 27,28

These efforts could lead to much improved lithium ion storage performances and be potentially suitable for other metal ions as well, in terms of both capacity and charge cycle stability. However, the gap between these bench-top studies and practical applications is still large. One of the most critical issues lies with the cleanness, facileness, and scalability of the materials and their synthesis, especially for the preparation of the very desirable $0-D$ and hollow-structured $\mathrm{MoS}_{2}$ /carbon materials, which are expected to provide a more efficient utilization of the conductive carbon substrate to support a larger content of active species as well as to form a better conductive network for electrochemical processes, compared with the other solid or non-spherical carbons. In a traditional fabrication process, a silica-based or other hard templates are often required, which are of high cost and requires hazardous treatments to remove. These approaches are economically unviable, energy-intensive, tedious and time-consuming, making them very difficult for mass production and meeting the criteria of green materials and chemistry. ${ }^{7}$ In this regard, it is very desirable and practically necessary to develop more convenient processing and synthesis technologies to produce $\mathrm{MoS}_{2}$ /carbon composites with rationally-designed and controllable structures, through a simple protocol that is low in cost, time efficient, and suitable for scale-up.

Based on these considerations, we herein report a facile solution-based method to prepare hierarchical porous $\mathrm{MoS}_{2}$ /carbon nanocomposites with vertical $\mathrm{MoS}_{2}$ nanosheets growth on the hollow carbon nanospheres supports, for the electrochemical storage of $\mathrm{Li}^{+}, \mathrm{Na}^{+}$and $\mathrm{K}^{+}$ions with high capacity, excellent rate performance, and stable cyclability.

\section{Experimental Section}

\section{Chemicals}

Hexadecyltrimethylammonium bromide (CTAB, 99\%), Pluronic F127, Cysteine, sodium molybdate dehydrate, resorcinol (99\%), ammonium hydroxide solution (25\%) and formaldehyde aqueous solution (37\%) were purchased from Sigma-Aldrich company. Water was purified by a Milli $Q$ system and had an electrical resistivity of $18.2 \mathrm{M} \Omega \mathrm{cm}$.

\section{Material synthesis}

Synthesis of $\mathrm{MoS}_{2} / \mathrm{C}-\mathbf{0 . 3}$ : In a typical synthesis, $0.13 \mathrm{~g}$ of CTAB, $0.1 \mathrm{~g} \mathrm{~F} 127$ and $0.6 \mathrm{~g}$ cysteine were dissolved in the solution containing $20 \mathrm{~mL}$ of water and $8 \mathrm{~mL}$ of ethanol. After above chemicals fully dissolved, $0.3 \mathrm{~g}$ of sodium molybdate dihydrate $\left(\mathrm{Na}_{2} \mathrm{MoO}_{4} \cdot 2 \mathrm{H}_{2} \mathrm{O}\right)$ was added. After stirring at $30{ }^{\circ} \mathrm{C}$ for 20 minutes, $0.2 \mathrm{~g}$ of resorcinol was added. After further stirring for $30 \mathrm{~min}, 0.28 \mathrm{~mL}$ of formaldehyde solution was added and stirred for $24 \mathrm{~h}$ at $30{ }^{\circ} \mathrm{C}$, and subsequently heated for $24 \mathrm{~h}$ at $220^{\circ} \mathrm{C}$ under a static condition in a Teflon-lined autoclave. The solid product $\mathrm{MoS}_{2} / \mathrm{RF}-0.3$ was recovered by centrifugation in water and ethanol for three times and then vacuum-dried at $30{ }^{\circ} \mathrm{C}$ for overnight. To obtain $\mathrm{MoS}_{2} / \mathrm{C}-0.3$ samples, the $\mathrm{MoS}_{2} / \mathrm{RF}-0.3$ is pyrolysed under $5 \% \mathrm{H}_{2}$ in argon flow in the tube furnace using a heating rate of $1{ }^{\circ} \mathrm{C} \mathrm{min}-1$ up to $350{ }^{\circ} \mathrm{C}$, dwelling for $2 \mathrm{~h}$, and resuming heating rate at $1{ }^{\circ} \mathrm{C} \mathrm{min}^{-1}$ up to $800{ }^{\circ} \mathrm{C}$ and then dwelling for $6 \mathrm{~h}$.

Synthesis of $\mathrm{MoS}_{2} / \mathrm{C}-\mathbf{0 . 1}$ and $\mathrm{MoS}_{2} / \mathrm{C}-\mathbf{0 . 4}$ : The synthesis process is similar to the protocol of $\mathrm{MoS}_{2} / \mathrm{C}-0.3$, the only difference is the amount of $\mathrm{Na}_{2} \mathrm{MoO}_{4} \bullet 2 \mathrm{H}_{2} \mathrm{O}$ used, 0.1 and $0.4 \mathrm{~g}$ of molybdate dihydrate $\left(\mathrm{Na}_{2} \mathrm{MoO}_{4} \cdot 2 \mathrm{H}_{2} \mathrm{O}\right)$ was added for $\mathrm{MoS}_{2} / \mathrm{C}-0.1$ and $\mathrm{MoS}_{2} / \mathrm{C}-0.4$, respectively.

\section{Material Characterizations}

Transmission electron microscopy (TEM) measurements were conducted on a JEM-2100F microscope (JEOL, Japan) operated at $200 \mathrm{kV}$. The samples for TEM measurement were suspended in ethanol and supported onto a holey carbon film on a $\mathrm{Cu}$ grid. Scanning electron microscopy (SEM) was taken with a JEOL-7800F field emission electron microscopy. X-ray photoelectron spectroscopy (XPS) Data was acquired using a Kratos Axis ULTRA X-ray Photoelectron Spectrometer, their atomic concentrations were calculated using the CasaXPS version 2.3.14 software and a Shirley baseline with Kratos library Relative Sensitivity Factors (RSFs). Peak fitting of the 
high-resolution data was also carried out using the Casa XPS software.

\section{The Electrochemical Performance of $\mathrm{MoS}_{2} / \mathrm{C}$ Nanospheres} Evaluation of $\mathrm{MoS}_{2} / \mathrm{C}$ nanoparticles as LIB anode materials: The working electrode slurry was mixed with the active material, Super P-Li, and poly(vinylidene fluoride) binder at a weight ratio of 8:1:1 in N-methylpyrrolidone (NMP). And then paste the slurry onto pure $\mathrm{Cu}$ foil, followed by drying at $100{ }^{\circ} \mathrm{C}$ under vacuum for hours. The electrochemical measurements were performed using a CR2016 type coin cell with Li metal as the counter/reference electrode, a Celgard 2400 membrane as the separator, and $1 \mathrm{M} \mathrm{LiPF}_{6}$ dissolved in ethylene carbonate/dimethyl carbonate (EC/DMC, $1: 1, \mathrm{v} / \mathrm{v}$ ) as the electrolyte. Cell assembly was performed in an argon-filled glove-box with water and oxygen concentrations below 1.0 $\mathrm{ppm}$. The electrodes were cut to $1 \times 1 \mathrm{~cm}^{2}$ and the loading amount of active materials in each electrode is around $1.2 \mathrm{mg}$. $80 \mu \mathrm{l}$ electrolyte was added in each cell. The galvanostatic charge-discharge tests were performed within a voltage window of 0.01-3.0 V on a NEWARE battery tester (NEWARE BTS-5V10 mA Model, Neware Technology Co., Ltd., China) at various current densities at room temperature. Electrochemical impedance spectroscopy (EIS) was performed with an electrochemical working station. The sinusoidal excitation voltage applied to the coin cells was $5 \mathrm{mV}$, with the frequency range from $100 \mathrm{kHz}$ to $0.01 \mathrm{~Hz}$. All the electrochemical tests were performed at room temperature.

Evaluation of $\mathrm{MoS}_{2} / \mathrm{C}$ nanoparticles as SIB anode materials: To test the electrochemical performance of samples as SIB anode materials, $\mathrm{MoS}_{2} / \mathrm{C}$ powder samples were mixed with super P-Li carbon black and a binder, carboxymethyl cellulose (CMC), in a weight ratio of 80:10:10 in a solvent (distilled water). The slurry was spread onto $\mathrm{Cu}$ foil substrates and these coated electrodes were dried in a vacuum oven at $100^{\circ} \mathrm{C}$ for 24 h. The electrodes were cut to $1 \times 1 \mathrm{~cm}^{2}$ and electrochemical half cells were assembled in an Ar-filled glove box (Innovative Technology, USA) using CR2032 coin cells with Na metal as the counter electrode, $1 \mathrm{M} \mathrm{NaClO}{ }_{4}$ dissolved in propylene carbonate (PC) with a $2 \%$ FEC (fluoroethylene carbonate) additive as the electrolyte, and a Whatman Glass Microfibre Filter (Grade GF/F) as a separator. The electrodes were cut to $1 \times 1 \mathrm{~cm}^{2}$ and the loading amount of active materials in each electrode is around $1.2 \mathrm{mg} .80 \mu \mathrm{L}$ electrolyte was added in each cell. The cells were galvanostatically discharged-charged in the range of 0.01-3.0 V with a Land battery testing system.

Evaluation of $\mathrm{MoS}_{2} / \mathrm{C}$ nanoparticles as PIB anode materials The working electrode slurry was mixed with the active material, Super P-Li, and poly(vinylidene fluoride) binder at a weight ratio of 8:1:1 in N-methylpyrrolidone (NMP). And then past the slurry onto pure $\mathrm{Cu}$ foil, followed by drying at $100{ }^{\circ} \mathrm{C}$ under vacuum for hours. The electrochemical half cells were assembled in an Ar-filled glove box (Innovative Technology, USA) using CR2032 coin cells with $\mathrm{K}$ metal as the counter electrode. $0.75 \mathrm{M} \mathrm{KPF}_{6}$ in a $1: 1(\mathrm{v} / \mathrm{v})$ mixture of ethylene carbonate (EC) and diethyl carbonate (DEC) was used as the electrolyte. The electrodes were cut to $1 \times 1 \mathrm{~cm}^{2}$ and the loading amount of active materials in each electrode is around $1.2 \mathrm{mg}$. $80 \mu \mathrm{L}$ electrolyte was added in each cell. The cells were galvanostatically discharged/charged in the potential range of 0.01-3.0 V with a Land battery testing system. Cyclic voltammogram (CV) tests were performed using Ivium-n-Stat electrochemical work stations.

\section{Results and Discussion}

\section{Material synthesis and characterization}

The hierarchical porous $\mathrm{MoS}_{2}$ /carbon hollow nanocomposite was prepared through a one-pot but multi-stepped selfassembly that occurred simultaneously during a hydrothermal process (Fig. 1). In this process, different precursors/surfactants played very important roles in forming the expected structure on the materials. Specifically, resorcinol and formaldehyde serve as the carbon precursors for the formation of hollow carbon structures. The surfactant CTAB and F127 play dual roles for the construction of the porous structure and directing the growth of $\mathrm{MoS}_{2}$ onto the external surface of carbon spheres with a nanosheet structure. ${ }^{15}$

The self-assembly of the individual precursor micelles is the key that leads to the resulted hollow and spherical structure. Cationic surfactants and block polymers are used as soft templates to form stabile micelles in the solvent mixture. In the first step, the $\mathrm{MoS}_{2}$ precursor (i.e. $\mathrm{MoO}_{4}{ }^{2-}$ ) chelates with the low-crosslinked resorcinol-formaldehyde (RF) clusters in the assistance of CTAB to form a Mo-RF hybrid complex, which then assembles on the micelle surface to form a Mo-RF hollow structure. In the next step, as the temperature goes higher during the hydrothermal treatment, the cysteine decomposes and releases $\mathrm{H}_{2} \mathrm{~S}$ to react with the Mo-RF complex precursor to in-situ form the $\mathrm{MoS}_{2} / \mathrm{RF}$ hollow spheres (Fig. S1). Finally, the soft template can be removed and the resulting C@MoS microspheres with well-controlled hollow structured can be obtained after the subsequent pyrolysis.

The morphology and microstructure of the $\mathrm{MoS}_{2}$ /carbon hollow microspheres (denoted $\mathrm{MoS}_{2} / \mathrm{C}-0.3$ ) were firstly investigated using SEM and TEM (Fig. 2). Under SEM, the $\mathrm{MoS}_{2}$ /carbon spheres are well-dispersed, with particle sizes of from $500 \mathrm{~nm}$ up to $1.5 \mu \mathrm{m}$ (Fig. 2a). From the cross-sectional view of the nanosphere, the large internal voids can be observed (Fig. 2a inset). The inside layer of the particle shell is dense and smooth, out of which is covered by the vertically grown nanosheets with a loose and hierarchical structure. From the TEM observations, all the particles clearly possess the hollow structure and the nanosheets are tightly attached on the shell (Fig. 2b). Even though the materials underwent intensive ultrasonication before the TEM observation, no detachment of the nanosheets was observed, which indicates the high structural integrity and mechanical stability of the material that is highly desirable for a durable battery cycling performance.

The fine structures of nanosheets were further studied under high resolution TEM (Fig. 2c). The nanosheets are 5-10 nm in thickness and ca. $50 \mathrm{~nm}$ in length, with a width of the similar scale. In each nanosheet, an interlayer distance of ca. $0.65 \mathrm{~nm}$ 
can be clearly identified, indicating its nature of $\mathrm{MoS}_{2}$ with a good crystallinity. Besides, these entangled nanosheets also have a large inter-sheet space of 5-20 nm. Consequently, the $\mathrm{MoS}_{2}$ nanosheets on the outside of this $\mathrm{MoS}_{2}$ /carbon nanosphere have an open and hierarchical characteristic, which could be beneficial for fast mass transportation and stress-buffering, thus favourable for good rate performance for repeated lithium ion insertion and desertion.

The heterostructure and elemental distribution of $\mathrm{MoS}_{2} /$ Carbon composites were also investigated by scanning transmission electron microscopy (STEM) and energy dispersive spectra (EDS) elemental mapping. As shown in Fig. $2 \mathrm{~d}$, the dense $\mathrm{MoS}_{2}$ nanosheets are vertically aligned on hollow carbon support and gives a much brighter contour compared with the inside section, confirming the lighter carbon elements mainly exits beneath the $\mathrm{MoS}_{2}$ nanosheets. Confirmed by the elemental mapping data (Fig. 2e-h), totally four elements were detected on the surface of the materials, including carbon, molybdenum, oxygen, and sulfur. Molybdenum and sulfur, which come from the $\mathrm{MoS}_{2}$, are found to be uniformly distribute on the surface of the material, giving an elemental mapping with exactly the same geometry as the TEM dark field image. Besides the heavier elements, carbon and oxygen also exist within the material. Carbon is from the hollow carbon support; while oxygen is commonly observed the carbon materials derived from the oxygen containing precursors (e.g. the RF resin) or surface oxidation. ${ }^{29}$ ${ }^{31}$ As a result of these observations, it is confirmed that the $\mathrm{MoS}_{2}$ nanosheets fully and homogeneously cover the surface of the $\mathrm{MoS}_{2} / \mathrm{C}$ microspheres. It proves that the one-pot synthesis can successfully achieve the vertical growth of thin $\mathrm{MoS}_{2}$ nanosheets on hollow carbon support, with the desirable 0-dimensional hierarchical structure.
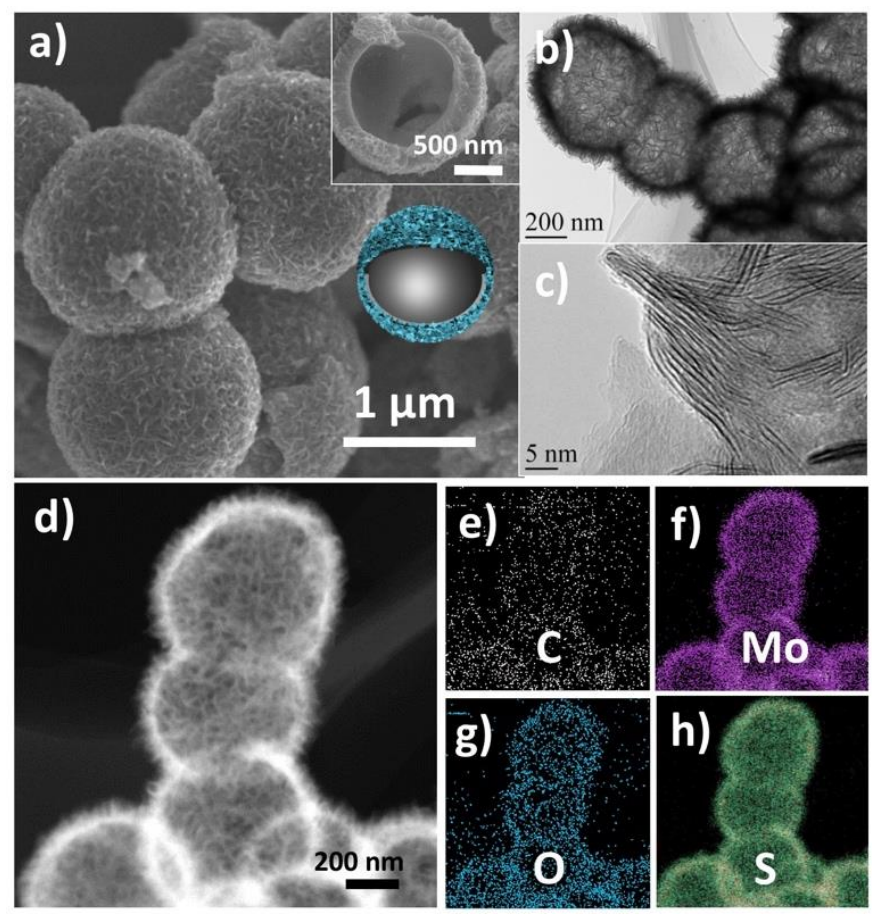

Fig. 2 Microstructure of the $\mathrm{MoS}_{2} /$ carbon nanosphere (MoS $/$ /C-0.3). a) SEM image of a broken particle showing its inner structure); b, c) TEM images at low and high magnifications, showing the whole particles and the detailed structures of the $\mathrm{MoS}_{2}$ nanosheets; d) dark field TEM image of the particles; and e-h) elemental mapping of $C$, Mo, $O$, and $S$ of the area in $d$ ).

More structural information of the material was revealed by Raman and X-ray diffraction (XRD). In the Raman spectrum (Fig. S2), the $\mathrm{MoS}_{2} / \mathrm{C}$ composite exhibits two broad bands at $1360 \mathrm{~cm}^{-1}$ (D-band) and $1598 \mathrm{~cm}^{-1}$ (G-band). The $\mathrm{D}$ band represents $\mathrm{sp}^{2}$ breathing modes of graphite, and is activated in the presence of defects within the graphitic structure, with the $G$ band related to the tangential stretching mode of $E_{2 g}$ phonon of $\mathrm{sp}^{2}$ carbon atoms. Apart from these, typical peaks from hexagonal layered $\mathrm{MoS}_{2}$ are also visible at 383 and 408 $\mathrm{cm}^{-1}$. The XRD results of $\mathrm{MoS}_{2} / \mathrm{C}$ microspheres show conspicuous peaks at $33^{\circ}$ and $59^{\circ}$, which are indexed to (100) and (110) planes of crystalline $\mathrm{MoS}_{2}$, respectively (Fig. S3). To determine the weight ratio of $\mathrm{MoS}_{2}$ to carbon in the samples, thermogravimetric analysis (TGA) was carried out from $25{ }^{\circ} \mathrm{C}$
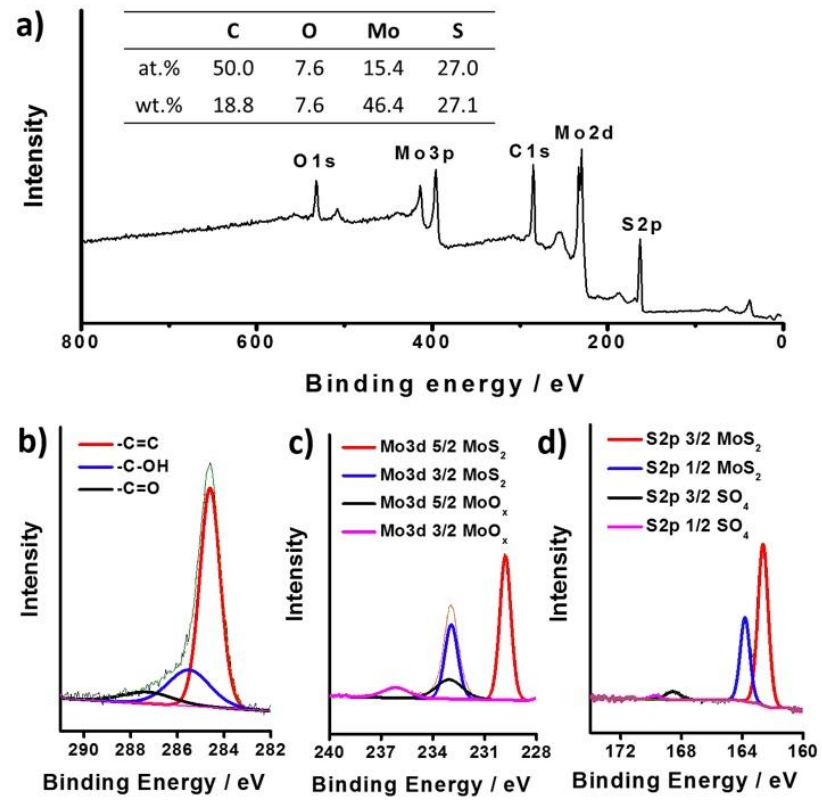

to $600{ }^{\circ} \mathrm{C}$ in air (Fig. S4). The residue of $\mathrm{MoS}_{2} / \mathrm{C}$ microspheres after thermal treatment in air is $\mathrm{MoO}_{3}$. A major weight loss is observed in the range of 300 to $400{ }^{\circ} \mathrm{C}$, which is due to the oxidation of $\mathrm{C}$ and $\mathrm{MoS}_{2}$ into $\mathrm{CO}_{2}$ and $\mathrm{MoO}_{3}$, respectively. TGA results show that the $\mathrm{MoS}_{2} / \mathrm{C}-0.3$ contain $69 \%$ of $\mathrm{MoS}_{2}$ and $31 \%$ of carbon. In contrast, $\mathrm{MoS}_{2} / \mathrm{C}-0.1$ and $\mathrm{MoS}_{2} / \mathrm{C}-0.4$ contain $46 \%$ and $74 \%$ of $\mathrm{MoS}_{2}$ respectively.

Fig. 3 Chemical composition and chemical states of the elements of $\mathrm{MoS}_{2} /$ carbon composite $\left(\mathrm{MoS}_{2} / \mathrm{C}-0.3\right)$. a) XPS survey scan of the sample, and inset is the content of each element obtained from the survey scan; b-d) high resolution XPS scan of C, Mo, and $\mathrm{S}$ elements.

The chemical composition and the chemical states of the elements in the material were further studied using XPS (Fig. 3). From the survey scan, the same elements ( $M o, S, C$, and O) can be identified, as from the EDS results, with the atomic proportions of 

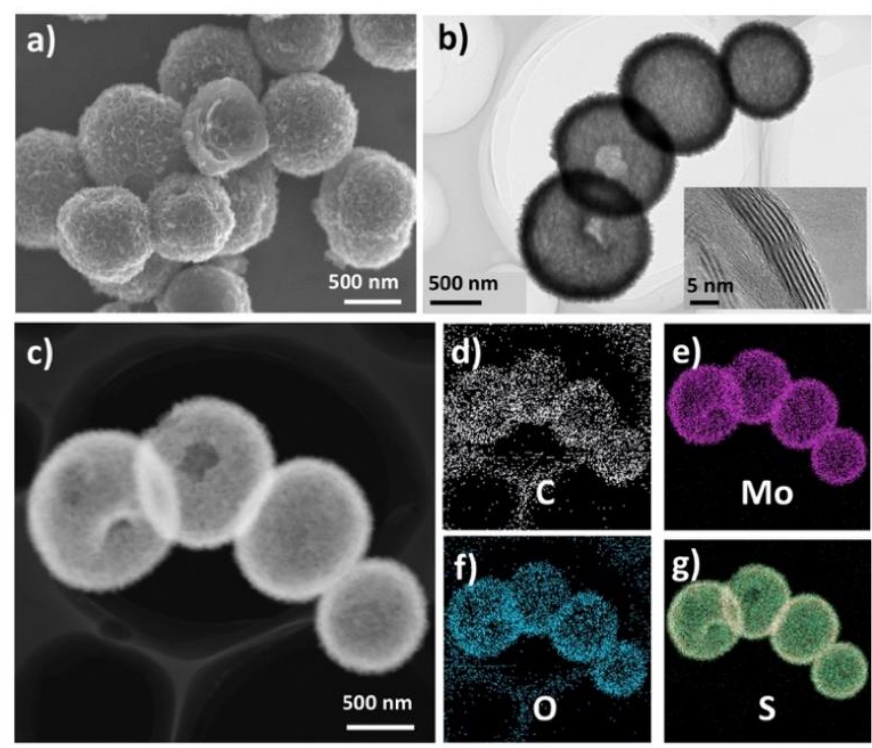

Fig. 4 Microstructure of the $\mathrm{MoS}_{2} /$ carbon nanosphere $\left(\mathrm{MoS}_{2} / \mathrm{C}-0.1\right)$. a) SEM image of the sample; b) TEM images of the sample, and inset is detailed structure of the $\mathrm{MoS}_{2}$ nanosheets; c) dark field TEM image of the particles; and $\mathrm{d}-\mathrm{g}$ ) elemental mapping of $\mathrm{C}, \mathrm{Mo}, \mathrm{O}$, and $\mathrm{S}$ of the area in $\mathrm{C}$ ).

50.0, 7.6, 15.4, and 27 at.\% for C, O, Mo, and S, respectively (Fig. 3a) We then obtained the high-resolution spectra of these elements to study their chemical states as illustrated in Fig. 3b-d. The C1s spectrum can be deconvoluted into three peaks, corresponding to $\mathrm{sp}^{2}$-hybridized graphitic carbon $(-\mathrm{C}=\mathrm{C})$ at ca. $294.6 \mathrm{eV}$ and carbon associated with functional groups (i.e. hydroxyl $(-\mathrm{C}-\mathrm{OH})$ group at ca. $285.6 \mathrm{eV}$ or carbonyl $(-\mathrm{C}=\mathrm{O})$ group at $287.4 \mathrm{eV}$, respectively) that inherited from the oxygen containing precursors (Fig. 3b).. ${ }^{29-31}$ On the other hand for Mo and S, characteristic peaks of the $\mathrm{MoS}_{2}$ (i.e. Mo3d 5/2 (229.8 eV) and Mo3d 3/2 (232.8 eV) representing the $\mathrm{Mo}^{4+}$ in $\mathrm{MoS}_{2}$; and S2p 3/2 (162.6 eV) and S2p 1/2 (163.8 eV) representing the $\mathrm{S}^{2-}$ in $\mathrm{MoS}_{2}$ ) have been observed, which further confirms the existence of $\mathrm{MoS}_{2}$ in this material (Fig. 3c, d). ${ }^{32,33}$ Apart from this, oxygen-containing species have also been identified in all these HR XPS spectra, which indicates the existence of oxidized Mo and $\mathrm{S}$ species (e.g. $\mathrm{MoO}_{x}$ and $\mathrm{SO}_{4}{ }^{2-}$ ), which might come from the surface oxidation of the materials in air or during fabrication, agreeing with the elemental mapping results.

To further understand the formation mechanism, we have prepared a series of analogue materials by tuning the
$\mathrm{Na}_{2} \mathrm{MoO}_{4}$ amount during the synthesis and investigated the resultant particles morphology and structure. By decreasing the $\mathrm{Na}_{2} \mathrm{MoO}_{4}$ quantity to $0.1 \mathrm{~g}$, the resulted material (denoted $\mathrm{MoS}_{2} / \mathrm{C}-0.1$ ) still shows a uniform particle size of ca. $1 \mu \mathrm{m}$ with a hollow structure (Fig. 4a, b). However, its shell thickness increased to $160 \mathrm{~nm}$ and the void space expand to $990 \mathrm{~nm}$. Similar to $\mathrm{MoS}_{2} / \mathrm{C}-0.3$, this $\mathrm{MoS}_{2} / \mathrm{C}-0.1$ sample still has $\mathrm{MoS}_{2}$ nanosheets grown on its surface, but in a horizontal manner with a smaller thickness corresponding to five $\mathrm{MoS}_{2}$ atomic layers as shown in the high magnification TEM image (Fig. 4b inset). The EDS elemental mapping further confirms the ultrathin layer $\mathrm{MoS}_{2}$ coating on the hollow carbon support (Fig. $4 \mathrm{c}-\mathrm{g}$ ). On the contrary, when the $\mathrm{NaMoO}_{4}$ quantity was increased to $0.4 \mathrm{~g}$, the resultant material (denoted $\mathrm{MoS}_{2} / \mathrm{C}$ 0.4) transfers to a complex hollow structure (Fig. 5). The TEM observations indicate the shell thickness of $\mathrm{MoS}_{2} / \mathrm{C}-0.4$ is around $105 \mathrm{~nm}$ and the void space decrease to $760 \mathrm{~nm}$ (Fig. 5a). The SEM images illustrate that $\mathrm{MoS}_{2}$ nanosheets are vertically coated on the carbon shells with a higher density (Fig. 5b, c). The elemental distribution of this complex yolkshell structured $\mathrm{MoS}_{2} / \mathrm{C}-0.4$ shows the $\mathrm{MoS}_{2}$ is also rich in yolk position compared to the $\mathrm{MoS}_{2} / \mathrm{C}-0.1$ and $\mathrm{MoS}_{2} / \mathrm{C}-0.3$ samples (Fig. 5d-h). In the absence of $\mathrm{Na}_{2} \mathrm{MoO}_{4}$, only normal microporous submicrospheres with an average particle size of $700 \mathrm{~nm}$ can be obtained (Fig. S5). Based on these observations, it is reasonable to believe that the concentration of Mo precursor would have a significant impact on the self-assembly and growth process, and thus modify the hollow yolk-shell structure of the $\mathrm{MoS}_{2} / \mathrm{C}$ composite. And this structural evolution also evidenced by $\mathrm{N}_{2}$ sorption isotherms, that the higher amount of $\mathrm{MoS}_{2}$ deposited on the surface of hollow carbon support would cause their $\mathrm{N}_{2}$ sorption isotherms transformed from the mixture of type I and type IV $\left(\mathrm{MoS}_{2} / \mathrm{C}-\right.$ 0.1 ) to type II. This might be because most of the micropores and mesopores on the hollow carbon support are blocked by increased $\mathrm{MoS}_{2}$ layer (Fig. S6). Their BET surface area also decreased from $239 \mathrm{~m}^{2} \mathrm{~g}-1\left(\mathrm{MoS}_{2} / \mathrm{C}-0.1\right)$ to $15 \mathrm{~m}^{2} \mathrm{~g}^{-1}\left(\mathrm{MoS}_{2} / \mathrm{C}-\right.$ $0.4)$.

\section{The Lithium Ion Storage Performance of $\mathrm{MoS}_{2} / \mathrm{C}$ Nanospheres}

Because of the large interlayer distance of the $\mathrm{MoS}_{2}$ nanosheets and the good electric conductivity of the carbon spheres, these $\mathrm{MoS}_{2} / \mathrm{C}$ microspheres are very suitable to be used as the anode material in a battery to store alkali-metal
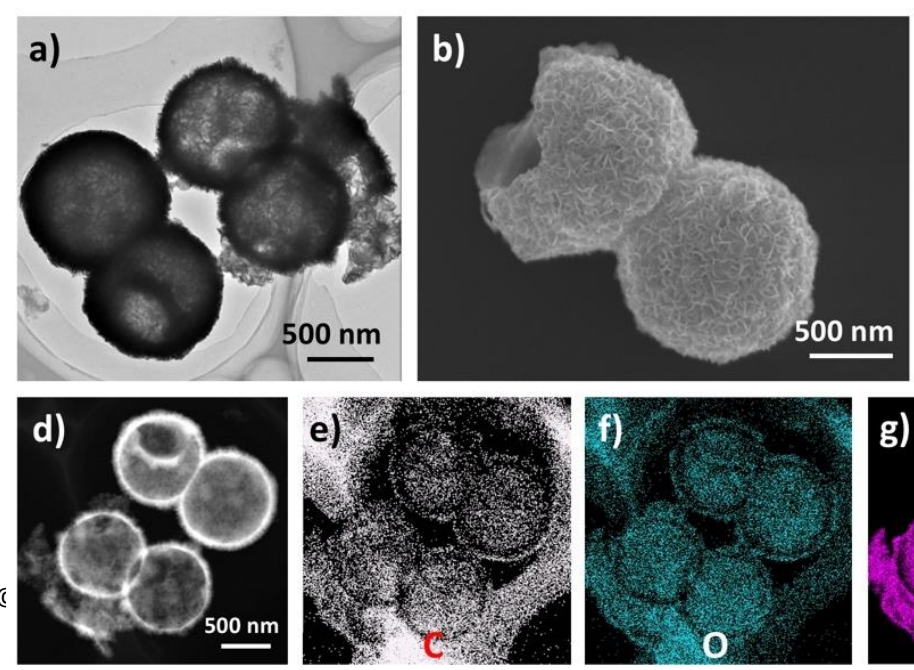
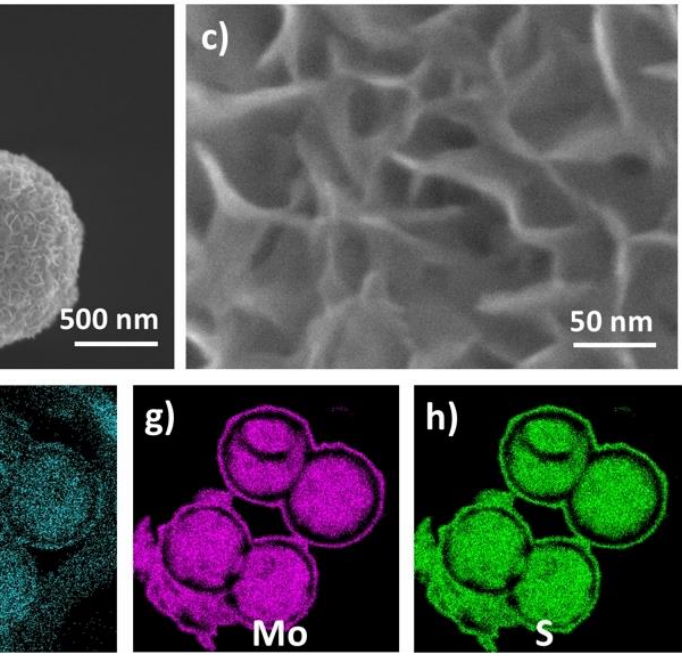

This journal is

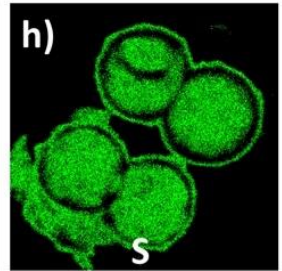

$3,00,1-3 \mid 5$

Fig. 5 Microstructure of the $\mathrm{MoS}_{2} /$ carbon nanosphere $\left(\mathrm{MoS}_{2} / \mathrm{C}-0.4\right)$. a) TEM image of the sample; b) Low magnification SEM image of the sample; c) High magnification SEM image of the sample surface; d) dark field STEM image of the particles; and e-h) elemental mapping of C, $\mathrm{O}, \mathrm{S}$ and Mo of the area in d) 
ions, especially for the ones with large dimensions (e.g. $\mathrm{Na}^{+}$ and $\left.\mathrm{K}^{+}\right)$. Firstly, we studied the materials' electrochemical lithium storage behaviour (Fig. 6, S7, and S8). When initially discharged to $0.01 \mathrm{~V}$ (i.e. lithiation of $\mathrm{MoS}_{2}$ ), the profile exhibits two plateaus at about $1.0 \mathrm{~V}$ and $0.5 \mathrm{~V}$, respectively (Fig. 6a, S7). The one at $0.5 \mathrm{~V}$ corresponds to the irreversible formation of the lithium-contained solid electrolyte interface (SEI) film on the surface of $\mathrm{MoS}_{2}$, whilst the other at $1.0 \mathrm{~V}$ reflects the reversible electrochemical conversion of $\mathrm{MoS}_{2}$ to metallic Mo and $\mathrm{Li}_{2} \mathrm{~S}$, which contributes to the actual lithium storage capacity. Besides, in the charge process, a voltage plateau at ca. $2.2 \mathrm{~V}$ is observed, which is due to the oxidation of metallic Mo into $\mathrm{MoS}_{2}$ and represents the reversible capacity of the materials. In the subsequent discharge processes, the plateau at $0.7 \mathrm{~V}$ disappears, which indicates that the irreversible formation of the SEI film only occurs in the first discharge
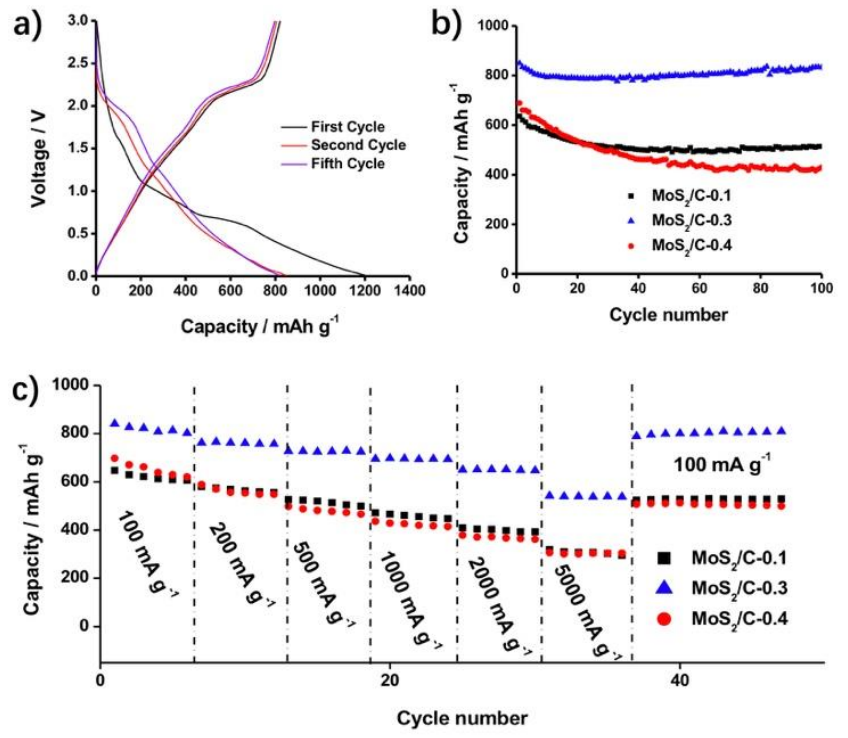

process, agreeing with the literature and the corresponding capacity mainly contributed by the reversible electrochemical insertion of lithium ions into the electrode. ${ }^{34}$

Fig. 6 Electrochemical lithium ion storage performance of $\mathrm{MoS}_{2} / \mathrm{C}-0.3$. a) the first, second, and fifth charge-discharge profile of the $\mathrm{MoS}_{2} / \mathrm{C}-0.3$ sample; b) the cycling performance of the materials; and c) the rate performance of the materials. The testing rates in a) and b) are $100 \mathrm{~mA} \mathrm{~g}^{-1}$.

The CV curve of the $\mathrm{MoS}_{2} / \mathrm{C}$ material was also collected between the voltage ranges of 0.01-3 V (Fig. S9). Upon the first discharge, three cathodic peaks appear at $0.9,0.5$, and $0.25 \mathrm{~V}$. The $0.9 \mathrm{~V}$ peak can be attributed to the phase transformation based on the reactions from $\mathrm{MoS}_{2}$ to $\mathrm{Li}_{x} \mathrm{MoS}_{2}$ resulting from the intercalation of $\mathrm{Li}$ ions into $\mathrm{MoS}_{2}$ layer. ${ }^{35}, 36$ With the proceeding of the electrode reaction, the peak at $0.5 \mathrm{~V}$ appears, which can be ascribed to the conversion of $\mathrm{Li}_{x} \mathrm{MoS}_{2}$ into $\mathrm{Li}_{2} \mathrm{~S}$ and metallic Mo. Moreover, the $0.25 \mathrm{~V}$ peak may be attributed to the ongoing reaction with the electrolyte solution to form the SEI film. ${ }^{37}$ In the subsequent discharge curves, the cathodic peaks shift to 1.9 and $1.2 \mathrm{~V}$, corresponding to the voltage plateau in the second and after discharge profiles. ${ }^{38,} 39$ This behaviour shows different lithiation mechanisms after the first cycle, and is in agreement with the charge-discharge profiles (Fig. 6a). In the anodic scans, two peaks at 1.54 and $2.25 \mathrm{~V}$ are observed. The broad weak peak at $1.54 \mathrm{~V}$ may be assigned to a partial oxidation state of Mo which forms $\mathrm{MoS}_{2}$; while the pronounced oxidation peak at $2.25 \mathrm{~V}$ is due to the formation of the sulfur. ${ }^{26,40,41}$ This $\mathrm{MoS}_{2} / \mathrm{C}$ material shows great structure stability after this charge-discharge process. As shown in the SEM image (Fig. S9), the hollow structure of carbon is well maintained and the $\mathrm{MoS}_{2}$ flakes are vertical standing after this charge-discharge process.

The reversible capacities of the materials can be obtained from the cycling stability test (Figs. $6 \mathrm{~b}, \mathrm{~S} 8$ and S10). The $\mathrm{MoS}_{2} / \mathrm{C}-0.3$ sample exhibits an initial capacity of $849 \mathrm{mAh} \mathrm{g}^{-1}$, and then decreased in the next few cycles, possibly due to the formation of the SEI layers that consumes lithium ions (Fig. S10). ${ }^{18,} 27$ Afterward, its capacity gradually increased throughout the subsequent cycles and finally reached $833 \mathrm{mAh}$ $\mathrm{g}^{-1}$ at the 100th cycle and $917 \mathrm{mAh} \mathrm{g}^{-1}$ at the 200th cycle. This gradual increase in capacity could possibly be attributed to the gradual infiltration of the electrolytes into the hierarchical structures of the $\mathrm{MoS}_{2} / \mathrm{C}$ composite as the test continued. Based on the capacities of the initial and 100th cycle, the calculated average capacity decay is as low as $0.019 \%$ per cycle, which is one of the lowest values reported in the literatures. ${ }^{5}, 18,19,24,25,27,28$ In contrast, the samples with a lower $\left(\mathrm{MoS}_{2} / \mathrm{C}-0.1\right)$ or higher $\left(\mathrm{MoS}_{2} / \mathrm{C}-0.4\right)$ content of $\mathrm{MoS}_{2}$ both showed an inferior performance compared with the $\mathrm{MoS}_{2} / \mathrm{C}-0.3$ material, in the aspects of capacity and cycling stability. Specifically, the $\mathrm{MoS}_{2} / \mathrm{C}-0.4$ sample showed a relatively higher initial capacity than that of $\mathrm{MoS}_{2} / \mathrm{C}-0.1$ sample, but its capacity decreased at a higher rate. The relatively higher initial capacity of $\mathrm{MoS}_{2} / \mathrm{C}-0.4$ might be attributed to the more $\mathrm{MoS}_{2}$ active material in this material. However, considering the insulating nature of $\mathrm{MoS}_{2}$, it is reasonable to assume that the excessive amount of $\mathrm{MoS}_{2}$ and lower amount of carbon on $\mathrm{MoS}_{2} / \mathrm{C}-0.4$ have caused its lower capacity due to the lower $\mathrm{MoS}_{2}$ utilization than the $\mathrm{MoS}_{2} / \mathrm{C}-0.3$ sample. On the other hand, the capacities of both the $\mathrm{MoS}_{2} / \mathrm{C}$ 0.1 and $\mathrm{MoS}_{2} / \mathrm{C}-0.3$ remained fairly stable after the initial decay in the first few cycles, while the capacity of $\mathrm{MoS}_{2} / \mathrm{C}-0.4$ continuously decreased throughout the testing, which indicates that excessive $\mathrm{MoS}_{2}$ would compromise the cycling stability of the hollow carbon/MoS 2 composites, which is mainly determined by the binding strength between the $\mathrm{MoS}_{2}$ sheets and the sub-surface carbon substrate.

The rate capability, which reveals how fast the materials can be charged and discharged, is another important factor determining the materials' performance. The rate performance of the material was evaluated at different charge and discharge speeds from 100 to $5000 \mathrm{~mA} \mathrm{~g}^{-1}$ (Fig. 6c). With the increasing of the testing rates, the capacity of all materials decreased. For the $\mathrm{MoS}_{2} / \mathrm{C}-0.3$, the capacity differences between various rates are the smallest. At a lower rate of 100 $\mathrm{mA} \mathrm{g}^{-1}$, it could deliver a high capacity of over $820 \mathrm{mAh} \mathrm{g}^{-1}$, close to the capacity obtained in the cycling stability test at the same rate (Fig. $6 \mathrm{~b}$ ). When the testing rate was significantly enlarged by 50 times to $5000 \mathrm{~mA} \mathrm{~g}^{-1}$, its capacity still remained at ca. $530 \mathrm{~mA} \mathrm{~g}^{-1}$ and this value could be instantly recovered 
when the testing rate went back to $100 \mathrm{~mA} \mathrm{~g}^{-1}$, which shows its rapid lithium storage capability owning to the good electronic conductivity and the hierarchical structure to facilitate the transfer of electrons and ions. In contrast, the $\mathrm{MoS}_{2} / \mathrm{C}-0.1$ and $\mathrm{MoS}_{2} / \mathrm{C}-0.4$ samples showed a much lower capacity at various rates, but $\mathrm{MoS}_{2} / \mathrm{C}-0.1$ possessed a relatively more stable capacity compared with $\mathrm{MoS}_{2} / \mathrm{C}-0.4$ as the test continued, which is also in agreement with the cycling stability test (Fig. 6b). This can be further confirmed by the EIS analysis (Fig. S11). The semicircle diameters in the high frequency region of Nyquist plots indicate that the $\mathrm{MoS}_{2} / \mathrm{C}-0.3$ microspheres exhibit faster charge-transfer kinetics than the $\mathrm{MoS}_{2} / \mathrm{C}-0.1$ and $\mathrm{MoS}_{2} / \mathrm{C}-0.4$ microspheres. Based on these results, it would be reasonable to deduce that the good performance of the $\mathrm{MoS}_{2} / \mathrm{C}-0.3$ sample would be a synergistic result of vertically standing $\mathrm{MoS}_{2}$ nanosheets stably anchoring on the hollow carbon support in this unique $\mathrm{MoS}_{2}$ and carbon heterostructure. Both horizontally oriented $\mathrm{MoS}_{2}\left(\mathrm{MoS}_{2} / \mathrm{C}-0.1\right)$ or complex hollow structure $\left(\mathrm{MoS}_{2} / \mathrm{C}-0.4\right)$ may impede their battery performance due to inefficient ionic and electronic transfer on their pathways, and should be avoided.

\section{Sodium and Potassium Ion Storage}

Evaluation of the materials capability in storing alkali-metal ions with larger dimensions was then conducted, firstly on the sodium ions (Fig. 7a). The first charge-discharge profile was collected at a current density of $25 \mathrm{~mA} \mathrm{~g}^{-1}$. In the discharge curve, it shows three plateaus at around 1.5-1.0 V, 0.8-0.4 V, and $0.4-0.01 \mathrm{~V}$, respectively. The first plateau corresponds to the intercalation of sodium ions to $\mathrm{MoS}_{2}$ interlayer, the second plateau is ascribed to the conversion reaction, and the plateau at $0.4-0.01 \mathrm{~V}$ is due to the insertion of $\mathrm{Na}$ ions into the interface between $\mathrm{Mo}$ and $\mathrm{Na}_{2} \mathrm{~S} .{ }^{42,}{ }^{43}$ However, the electrode delivers a relatively large irreversible capacity in the first discharge, which is generally recognized to originate from the decomposition of electrolyte to form the SEI film. ${ }^{39,42}$ To better understand the $\mathrm{Na}^{+}$insertion and desertion mechanism on this $\mathrm{MoS}_{2} / \mathrm{C}$, the sodiation/de-sodiation process was further evaluated by $\mathrm{CV}$ measurements for the initial three cycles respectively (Fig. S12a). The CV curve exhibits three reduction peaks at 1.2-0.7, 0.7-0.4 and 0.4-0.01 $\mathrm{V}$ and two corresponding oxidation peaks at 1.7 and $2.2 \mathrm{~V}$ in the first cycle. In the subsequent cycles, two reduction peaks at 0.7 and $1.7 \mathrm{~V}$ and two oxidations at 1.7 and $2.2 \mathrm{~V}$ are observed. The $\mathrm{CV}$ peaks are stable in the subsequent cycles, demonstrating a good reversible and stable sodiation/de-sodiation processes. Based on these observations, the overall sodiation mechanism can be represented as follows. ${ }^{44}$

$$
\begin{aligned}
& \mathrm{MoS}_{2}+x \mathrm{Na}^{+}+x \mathrm{e}^{-} \rightarrow \mathrm{Na}_{x} \mathrm{MoS}_{2} \\
& \mathrm{Na}_{x} \mathrm{MoS}_{2}+(4-\mathrm{x}) \mathrm{Na}^{+}+(4-x) \mathrm{e}^{-} \rightarrow 2 \mathrm{Na}_{2} \mathrm{~S}+\mathrm{Mo}
\end{aligned}
$$

The materials rate performance can be firstly revealed by the charge-discharge profiles at different rates. These profiles of the electrode still exhibit the typical charge-discharge shape, which indicates that the sodium insertion/desertion undergoes the similar processes at both low and high current rates (Fig. 7b). We then evaluated the rate capability of the material by step-wisely increasing the testing current density from 25 to $1000 \mathrm{~mA} \mathrm{~g}^{-1}$ (Fig. 7c). At each rate stage, the electrode delivers very stable and reversible capacity of 450 at 25,397 at 50, 344 at 100,276 at 300,241 at 500 , and $200 \mathrm{mAh} \mathrm{g}^{-1}$ at $1000 \mathrm{~mA} \mathrm{~g}^{-1}$, respectively. Remarkably, when the current rate is brought back to $25 \mathrm{~mA} \mathrm{~g}^{-1}$, the capacity swiftly recovers to $382 \mathrm{mAh} \mathrm{g-}$ 1 , showing a strong tolerance for the rapid $\mathrm{Na}^{+}$ion extraction/insertion even after many repeated cycles. The cycling stability of the material in the potential range of 0.01 - a)

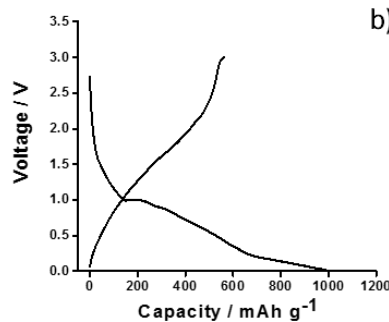

c)

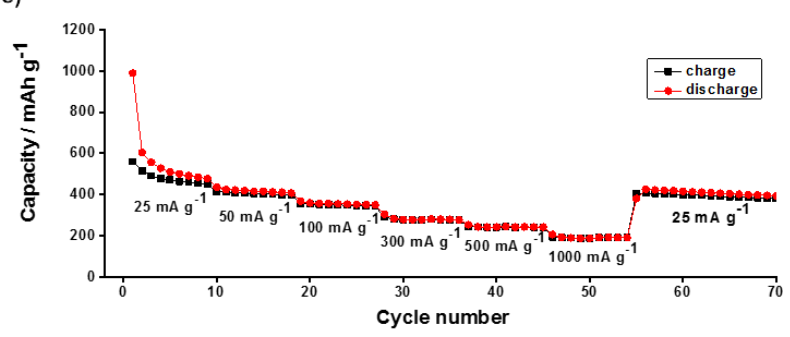

b)

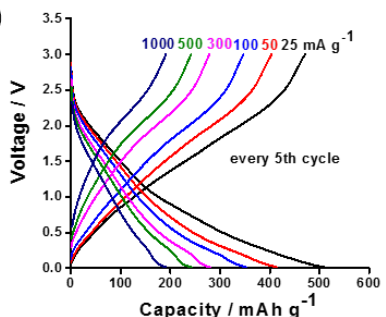

$3.0 \mathrm{~V}$ vs. $\mathrm{Na} / \mathrm{Na}^{+}$and cycling performance and corresponding charge-discharge profiles of the electrode can be found in supporting information (Figs. S12b, c). A reversible capacity of $291 \mathrm{mAh} \mathrm{g}^{-1}$ was obtained after 50 cycles at a current rate of $50 \mathrm{~mA} \mathrm{~g}^{-1}$.

Fig. 7 Electrochemical performance of $\mathrm{MoS}_{2} / \mathrm{C}-0.3$ electrodes in Na-ion cells: (a) corresponding 1st discharge/charge potential profile at $25 \mathrm{~mA} \mathrm{~g}^{-1}$; and (b) corresponding discharge/charge potential profiles of the 5th cycle obtained at different current rates; (c) rate capability at different current rates ranging from 25-1000 $\mathrm{mA} \mathrm{g}^{-1}$ and back to $25 \mathrm{~mA} \mathrm{~g}^{-1}$.

Subsequently, the $\mathrm{MoS}_{2} / \mathrm{C}$ material was further charged and discharged using the even larger $\mathrm{K}^{+}$ions at a constant current density of $20 \mathrm{~mA} \mathrm{~g}^{-1}$ to study its suitability for KIB applications (Fig. S13). It is demonstrated that the electrode is capable of delivering a reversible capacity of $278 \mathrm{mAh} \mathrm{g}^{-1}$ at $20 \mathrm{~mA} \mathrm{~g}^{-1}$ after 20 cycles (Fig. S13a). The corresponding charge-discharge potential profiles are depicted in Fig. S13b. The first discharge/charge capacities were measured to be 670/399 $\mathrm{mAh} \mathrm{g}^{-1}$ with an initial Coulombic efficiency of $59 \%$. This low initial Coulombic efficiency may be due to the formation of SEI layer on the electrode surface, similar as the cases of the insertion of other ions. ${ }^{45-49}$ This is also supported by the CV analysis (Fig. S13c). The CV profile in the first discharge (fist cathodic scan) suggests that $\mathrm{K}^{+}$intercalation into $\mathrm{MoS}_{2}$ may proceed via a series of steps. The intercalation has an initial broad plateau between 1.0-0.01 V, which is composed of another two small plateaus at $0.5 \mathrm{~V}$ and $0.25 \mathrm{~V}$. From the 
second cycle, this broad plateau at 1.0-0.01 V disappeared, suggesting the SEI layer formation in the first discharge. Apart from this, the material anodic curves all show two peaks at 1.09 and $1.69 \mathrm{~V}$, suggesting its reversible $\mathrm{K}^{+}$ion storage capability. ${ }^{13}$

\section{Conclusions}

In summary, we have developed a facile approach to prepare $\mathrm{MoS}_{2}$ /carbon hollow microspheres with unique verticallyaligned $\mathrm{MoS}_{2}$ directly grown on the carbon substrate, for the electrochemical storage of a serial of alkali-metal ions with high capacity, excellent rate performance, and stable cyclability as demonstrated in Tables S1-S3. The morphology and microstructure of the $\mathrm{MoS}_{2}$ /carbon microspheres can be easily controlled by simply tuning the concentrations of the precursors in the self-assembly process. The as-prepared material shows an excellent performance for $\mathrm{Li}^{+}$storage. At $100 \mathrm{~mA} \mathrm{~g}^{-1}$, it possesses a high initial capacity up to $800 \mathrm{mAh} \mathrm{g}$ 1 , with a very small capacity decay as low as $0.019 \%$ per cycle during 100 cycles. At a substantially higher rate of $5000 \mathrm{~mA} \mathrm{~g}^{-1}$, it still delivers a capacity of over $530 \mathrm{mAh} \mathrm{g}^{-1}$. Furthermore, the material also presents a highly reversible $\mathrm{Na}^{+} / \mathrm{K}^{+}$ion storage capability, making it very suitable for next-generation secondary batteries. As a result of these excellent characteristics, these hollow $\mathrm{MoS}_{2}$ /carbon composites would be very promising for the future energy storage and conversion applications.

\section{Acknowledgements}

This work was financially supported by the Australian Research Council (ARC) through Discovery Project (DP) and Discovery Early Career Researcher Award (DECRA, No. DE170100871) programs, and Deakin University CRGS research Funding. Dr Qian Lin is acknowledged for her assistance of Li-ion battery performance test.

\section{Notes and references}

1. J. Liang, S. Z. Qiao, G. Q. Lu and D. Hulicova-Jurcakova, in Novel Carbon Adsorbents, ed. J. M. D. Tascón, Elsevier, Oxford, 2012, DOI: 10.1016/B978-0-08-097744-7.00018-1, 549-581.

2. J. Liang, R. Zhou, D. Hulicova-Jurcakova and S. Qiao, in Producing Fuels and Fine Chemicals from Biomass Using Nanomaterials, CRC Press, 2013, DOI: 10.1201/b15585-5, 59-94.

3. P. G. Bruce, S. A. Freunberger, L. J. Hardwick and J. M. Tarascon, Nat. Mater., 2012, 11, 19-29.

4. J. M. Tarascon and M. Armand, Nature, 2001, 414, 359-367.

5. J. Liang, Z. H. Sun, F. Li and H. M. Cheng, Energy Storage Mater., 2016, 2, 76-106.

6. W. Lei, W. Xiaowei, L. G. Qiang, L. H. Ze, L. Ji and D. S. Xue, Surf. Innov., 2018, 0, 1-6.

7. X. Y. Yu, L. Yu and X. W. Lou, Small Methods, 2017, 1, 1600020.

8. L. Yang, S. Wang, J. Mao, J. Deng, Q. Gao, Y. Tang and O. G. Schmidt, Adv. Mater., 2013, 25, 1180-1184.

9. C. Zhang, Z. Wang, Z. Guo and X. W. Lou, ACS Appl. Mater Inter., 2012, 4, 3765-3768.
10. X. Cao, C. Tan, X. Zhang, W. Zhao and H. Zhang, Adv. Mater., 2016, 28, 6167-6196.

11. X. Xie, T. Makaryan, M. Zhao, K. L. Van Aken, Y. Gogotsi and G. Wang, Adv. Energy Mater., 2016, 6, 1502161.

12. S. H. Choi, Y. N. Ko, J. K. Lee and Y. C. Kang, Adv. Funct. Mater., 2015, 25, 1780-1788.

13. X. Ren, Q. Zhao, W. D. McCulloch and Y. Wu, Nano Res., 2017, 10, 1313-1321.

14. J. N. Coleman, M. Lotya, A. O'Neill, S. D. Bergin, P. J. King, U. Khan, K. Young, A. Gaucher, S. De, R. J. Smith, I. V. Shvets, S. K. Arora, G. Stanton, H. Y. Kim, K. Lee, G. T. Kim, G. S. Duesberg, T. Hallam, J. J. Boland, J. J. Wang, J. F. Donegan, J. C. Grunlan, G. Moriarty, A. Shmeliov, R. J. Nicholls, J. M. Perkins, E. M. Grieveson, K. Theuwissen, D. W. McComb, P. D. Nellist and V. Nicolosi, Science, 2011, 331, 568-571.

15. T. Yang, L. Wei, L. Jing, X. Zhang, M. Tang, M. J. Monteiro, Y. Chen, Y. Wang, S. Gu, D. Zhao, H. Yang, J. Liu and G. Q. M. Lu, Angew. Chem. Int. Edit., 2017, 56, 8459-8463.

16. C. Tan, X. Cao, X. J. Wu, Q. He, J. Yang, X. Zhang, J. Chen, W. Zhao, S. Han, G. H. Nam, M. Sindoro and H. Zhang, Chem. Rev., 2017, 117, 6225-6331.

17. W. Sun, Z. Hu, C. Wang, Z. Tao, S. L. Chou, Y.-M. Kang and H.-K. Liu, ACS Appl. Mater. Inter., 2016, 8, 22168-22174.

18. L. Zhang and X. W. Lou, Chem. - Eu. J., 2014, 20, 5219-5223.

19. Z. Yufei, W. Ye, Y. Jun, S. Wenhui, Y. Huiying, H. Wei and D. Xiaochen, 2D Mater., 2016, 3, 024001.

20. L. Yu, H. Hu, H. B. Wu and X. W. Lou, Adv. Mater., 2017, 29, 1604563

21. C. Zhu, X. Mu, P. A. van Aken, Y. Yu and J. Maier, Angew. Chem. Int. Edit., 2014, 53, 2152-2156.

22. C. Zhu, X. Mu, P. A. van Aken, J. Maier and Y. Yu, Adv. Energy Mater., 2015, 5, 1401170.

23. L. Jiang, B. Lin, X. Li, X. Song, H. Xia, L. Li and H. Zeng, ACS Appl. Mater. Inter., 2016, 8, 2680-2687.

24. H. Li, K. Yu, H. Fu, B. Guo, X. Lei and Z. Zhu, J. Phys. Chem. C, 2015, 119, 7959-7968.

25. Y. Liu, Y. Zhao, L. Jiao and J. Chen, J. Mater. Chem. A, 2014, 2, 13109-13115.

26. D. Sun, D. Ye, P. Liu, Y. Tang, J. Guo, L. Wang and H. Wang, Adv. Energy Mater., DOI: 10.1002/aenm.201702383, 1702383.

27. J. Wang, J. Liu, J. Luo, P. Liang, D. Chao, L. Lai, J. Lin and Z. Shen, J. Mater. Chem. A, 2015, 3, 17534-17543.

28. Z. L. Wang, D. Xu, J. J. Xu and X. B. Zhang, Chem. Soc. Rev., 2014, 43, 7746-7786.

29. J. Liang, R. F. Zhou, X. M. Chen, Y. H. Tang and S. Z. Qiao, Adv. Mater., 2014, 26, 6074-6079.

30. J. Liang, X. Du, C. Gibson, X. W. Du and S. Z. Qiao, Adv. Mater., 2013, 25, 6226-6231.

31. J. Liang, L. Yin, X. Tang, H. Yang, W. Yan, L. Song, H. M. Cheng and F. Li, ACS Appl. Mater. Inter., 2016, 8, 25193-25201.

32. J. G. Choi and L. T. Thompson, Appl. Surf. Sci., 1996, 93, 143149.

33. M. El Azhar, M. Traisnel, B. Mernari, L. Gengembre, F. Bentiss and M. Lagrenée, Appl. Surf. Sci., 2002, 185, 197-205.

34. F. Sun, Y. Wei, J. Chen, D. Long, L. Ling, Y. Li and J. Shi, Nanoscale, 2015, 7, 13043-13050.

35. U. K. Sen and S. Mitra, ACS Appl. Mater. Inter., 2013, 5, 12401247.

36. S. Hu, W. Chen, J. Zhou, F. Yin, E. Uchaker, Q. Zhang and G. Cao, J. Mater. Chem. A, 2014, 2, 7862-7872.

37. L. Hu, Y. Ren, H. Yang and Q. Xu, ACS Appl. Mater. Inter., 2014, 6, 14644-14652. 
38. W. Qiu, J. Jiao, J. Xia, H. Zhong and L. Chen, RSC Adv., 2014, 4, 50529-50535.

39. W. Qin, T. Chen, L. Pan, L. Niu, B. Hu, D. Li, J. Li and Z. Sun, Electrochim. Acta, 2015, 153, 55-61.

40. J. Wang, J. Liu, D. Chao, J. Yan, J. Lin and Z. X. Shen, Adv. Mater., 2014, 26, 7162-7169.

41. Y. Tang, D. Wu, Y. Mai, H. Pan, J. Cao, C. Yang, F. Zhang and X. Feng, Nanoscale, 2014, 6, 14679-14685.

42. J. Wang, C. Luo, T. Gao, A. Langrock, A. C. Mignerey and C. Wang, Small, 2015, 11, 473-481.

43. P. R. Kumar, Y. H. Jung and D. K. Kim, RSC Adv., 2015, 5, 7984579851.

44. L. David, R. Bhandavat and G. Singh, ACS Nano, 2014, 8, 17591770.

45. G. Pistoia, J. Electrochem. Soc., 1971, 118, 153-158.

46. K. Xu, Chem. Rev., 2004, 104, 4303-4418.

47. H. Liu, X. Liu, W. Li, X. Guo, Y. Wang, G. Wang and D. Zhao, Adv. Energy Mater., 2017, 7, 1700283.

48. H. Tian, H. Liu, T. Yang, J. P. Veder, G. Wang, M. Hu, S. Wang, M. Jaroniec and J. Liu, Mater. Chem. Front., 2017, 1, 823-830.

49. L. Wang, Z. Zhou, X. Yan, F. Hou, L. Wen, W. Luo, J. Liang and S. X. Dou, Energy Storage Mater., 2018, 14, 22-48. 